\title{
Simultaneous Evaluation of the Production of Squalene and Fatty Acids by Aurantiochytrium
}

\section{Gabriel Martins ${ }^{1}$, Maria C. Paulo ${ }^{1}$, Mária Padilha ${ }^{2}$, Joana Coutinho ${ }^{1}$, Carlos Cardoso ${ }^{2 *}$, Narcisa M. Bandarra ${ }^{2}$, Irineu Batista ${ }^{2}$}

${ }^{1}$ DEPSIEXTRACTA Tecnologias Biológicas Lda, Zona Industrial do Monte da Barca, lote 62, rua H, Coruche, Portugal

${ }^{2}$ Division of Aquaculture and Valorization (DivAV), Portuguese Institute for the Sea and Atmosphere (IPMA, I.P.), Rua Magalhães Ramalho, 6, 1495-006 Lisboa, Portugal

*Corresponding author: Carlos Cardoso, Rua Magalhães Ramalho, 6, 1495-006 Lisboa, Portugal, Tel: +351 96383 74 60; E-mail: carlos.cardoso@ipma.pt

\begin{abstract}
:
The growth, squalene content and fatty acid profile of Aurantiochytrium sp. produced at 26 and $30^{\circ} \mathrm{C}$, two salinities $(1.5$ and $3.5 \%)$ and three initial glucose concentrations $(2,3$, and $4 \%)$ were investigated. This study aimed to simultaneously analyse and compare the production of squalene and DHA, offering an uncommon integrated overview of the production possibilities of this microorganism. The highest biomass production was achieved after 72 or 96 hours at both temperatures and higher biomass productivity at 72 hours was recorded in the growth media with lower salinity. Total lipid content of dried biomass was $c a .35 \%$ and triacylglycerols accounted for about $65 \%$ of total lipids. Saturated and polyunsaturated fatty acids accounted for almost all fatty acids. The sum of DHA and DPA n- 6 percentages represented about $90 \%$ of total PUFA. The presence of a high percentage of odd fatty acids $(\mathrm{ca} .30 \%)$ is another typical feature of thraustochytrids. The highest production of squalene $(7.3 \mathrm{~g} / 100 \mathrm{~g}$ and $250 \mathrm{mg} / \mathrm{L})$ was achieved in the trial with $1.5 \%$ salinity, $3 \%$ of initial glucose concentration, at $26^{\circ} \mathrm{C}$ and after 48 hours of growth. On the other hand, the highest productivity of PUFA, DHA and DPA n-6 was achieved in the growth medium with low salinity and 3\% of initial glucose concentration at $30^{\circ} \mathrm{C}$ after 96 hours of growth. Accordingly, there is a possibility to combine culture conditions in a way that both maximizes squalene and DHA production, thereby providing cues for an environmentally sustainable bio-refinery approach.
\end{abstract}

Keywords: Biomass; Squalene; Fatty acids

\section{Introduction}

Some thraustochytrid strains, particularly those of the Thraustochytriaceae family, have been recognized as a promising alternative for the production of squalene $\left.\mathrm{C}_{30} \mathrm{H}_{50}\right)$. This triterpene is commercially produced from the liver oil of deepsea sharks, plant seed oils or wastes from olive oil production. However, the continuous supply of these raw materials is uncertain as a result of several factors. Squalene and squalane, its hydrogenated form, are currently used in the cosmetic industry as moisturising agent and emollient. It is also applied in medicinal products ${ }^{[1]}$ and it was demonstrated that squalene can inhibit chemically induced skin, lung and colon tumorigenesis in rodents ${ }^{[2]}$ and as the major factor in the cancer risk-reducing effect $^{[3]}$. Thraustochytrid strains are also known as producers of microbial oils particularly rich in docosahexaenoic acid (DHA) [4]. The importance of DHA derives from its health benefits particularly in the development of neural and retinal functions ${ }^{[5]}$ and to improve the learning capacity of school-aged children, inhibitor of carcinomas and exhibiting chemo-protective activities.

The growth conditions of thraustochytrid strains have been studied ${ }^{[6]}$ but their nutritional requirements are species specific. Besides these studies have focused on the production of polyunsaturated fatty acids or squalene which are synthesized by two different metabolic pathways which present differences in their nutrient requirements. Thus, it was objective of the current study to investigate the effect of different growth conditions (glucose concentration, salinity, and temperature) on the production of squalene by Aurantiochytrium sp. and also to evaluate its performance on the production of DHA, thereby yielding an integrated overview of the production possibilities of Aurantiochytrium $\mathrm{sp}$. for a maximal valorization of its biomass.

\section{Received date: December 06, 2017 \\ Accepted Date: March 12, 2018 \\ Published Date: March 16, 2018}

Citation: Martins, G. Simultaneous Evaluation of the Production of Squalene and Fatty Acids by Aurantiochytrium. (2018) J Marine Biol Aquacult 4(1): 14- 20.

Copy Rights: (C) 2018 Cardoso, C. This is an Open access article distributed under the terms of Creative Commons Attribution 4.0 International License. 


\section{Materials and Methods}

The strain Aurantiochytrium sp. ATCC ${ }^{\circledR}$ PRA-276 $6^{\mathrm{TM}}$ was provided by the American Type Culture Collection (ATCC Manassas, VA, USA). Seed cultures were grown in Erlenmeyer flasks $(250 \mathrm{~mL})$ containing $50 \mathrm{~mL}$ of ATCC medium no. $790(1.0$ $\mathrm{g} / \mathrm{L}$ yeast extract; $1.0 \mathrm{~g} / \mathrm{L}$ peptone; $5.0 \mathrm{~g} / \mathrm{L}$ glucose), with a seawater concentration of $1.5 \%$, at $30^{\circ} \mathrm{C}$ with rotational shaking at $150 \mathrm{rpm}$ for 2.5 days. After this incubation period, the microorganism culture was mixed with glycerol at a ratio of $3: 1$ and kept at $-80^{\circ} \mathrm{C}$. The culture was also maintained on Potato Dextrose Agar (PDA) slants at $4^{\circ} \mathrm{C}$ and monthly subcultured.

\section{Culture conditions}

Aurantiochytrium sp. was cultivated in heterotrophic conditions in Erlenmeyer flasks $(250 \mathrm{~mL})$ with the culture medium consisting of (per liter) $0.1 \mathrm{~g} \mathrm{NaHCO}_{3}, 1 \mathrm{~g} \mathrm{KCl}, 5 \mathrm{~g} \mathrm{Mg}$ $\mathrm{SO}_{4} .7 \mathrm{H}_{2} \mathrm{O}, 0.3 \mathrm{~g} \mathrm{KH}_{2} \mathrm{PO}_{4}, 0.2 \mathrm{~g}\left(\mathrm{NH}_{4}\right)_{2} \mathrm{SO}_{4}, 0.3 \mathrm{~g} \mathrm{CaCl}_{2} .2 \mathrm{H}_{2} \mathrm{O}$, $2 \mathrm{~g}$ monosodium glutamate, $2 \mathrm{~g}$ yeast extract and 20,30 or $40 \mathrm{~g}$ glucose solubilized in seawater with salinity $1.5 \%$ (LS) or $3.5 \%$ (HS). The growth medium was inoculated with $5 \%(\mathrm{v} / \mathrm{v})$ of an exponentially growing inoculum. The inoculum was prepared in an Erlenmeyer flask with $50 \mathrm{~mL}$ of ATCC medium no. 790 for $60 \mathrm{~h}$ in an orbital shaker at $150 \mathrm{rpm}$. Cultures were incubated at 26 and $30^{\circ} \mathrm{C}$ in an orbital shaker at $150 \mathrm{rpm}$ in the dark. The majority of microalgae growth was stopped after 168 hours but for others the growth period was shortened to 96 hours. The results are average values based on the simultaneous cultivation of three replicates.

\section{Evaluation of growth}

The biomass growth was followed by measuring the optical density of the culture medium at $600 \mathrm{~nm}$ every 24 hours. For the determination of Dry Weight (DW) the biomass was centrifuged at $9800 \times \mathrm{g}$ for $15 \mathrm{~min}$, at $4^{\circ} \mathrm{C}$, washed twice with distilled water and lyophilized over 24 hours.

\section{Glucose and lipid content determination}

Residual glucose concentration in culture media was determined by the 3,5-dinitrosalicylic acid method ${ }^{[7]}$. The lipid content was evaluated after extraction by the Bligh and Dyer $\operatorname{method~}^{[8]}$.
Lipid class separation and determination of fatty acid profile

The lipids classes were separated by thin-layer chromatography and identified as described by Costa et al. ${ }^{[9]}$. Fatty acid profile was determined in lyophilized cells. Fatty acids methyl esters were prepared by transesterification according to Lepage and Roy ${ }^{[10]}$ as modified by Cohen et al. ${ }^{[1]]}$. The analysis of methyl esters was performed as previously described ${ }^{[12]}$. Fatty acid methyl esters were identified by chromatographic comparison with authentic standards (Sigma Chemical Co.). The quantities of individual FAMEs were estimated from the peak areas on the chromatogram using 23:0 fatty acid as the internal standard.

\section{Determination of squalene content}

The method followed in the quantification of squalene was done as described by Chen et al ${ }^{[6]}$ Squalene quantification was calculated by comparison with a calibration curve made with a Sigma squalene standard.

\section{Statistical analysis}

Data were analyzed using STATISTICA 6 software (Statsoft, Inc., Tulsa, OK74104, USA). One-way ANOVA was used to determine significant differences $(p<0.05)$ due to temperature for each set of salinity/initial glucose and a factorial ANOVA was applied to determine significant differences $(\mathrm{p}<$ 0.05 ) between salinity (low and high) and initial glucose (20, 30 , and $40 \mathrm{~g} / \mathrm{L}$ ) levels for each temperature. Each ANOVA was followed by Tukey HSD test. When data did not meet normal distribution and homoscedasticity, differences were tested by a non-parametric comparisons tests ${ }^{[13]}$.

\section{Results}

\section{Effect of culture conditions on growth}

The evolution of Aurantiochytrium sp. biomass produced at three different levels of glucose and two salinities at $26^{\circ} \mathrm{C}$ and $30^{\circ} \mathrm{C}$ is presented in figure 1 . At both temperatures the highest biomass production was attained after 72 or 96 hours. The results obtained also evidenced the highest biomass production achieved in the growth media with the lower salinity. Accordingly significant lower productivity was achieved after 72 hours in the higher salinity growth media as shown in [Table 1]. On the other hand, in the low salinity media similar productivities were obtained at $26^{\circ} \mathrm{C}$ regardless the initial glucose content. However, at $30^{\circ} \mathrm{C}$ significant differences were recorded being the highest productivity attained in the $3 \mathrm{GLS}$ trial.

Table 1: Productivity and glucose consumption as a function of initial glucose concentration and salinity in growth experiments at 26 and $30^{\circ} \mathrm{C}$.

\begin{tabular}{|c|c|c|c|c|c|}
\hline \multirow[b]{2}{*}{ Temperature $\left({ }^{\circ} \mathrm{C}\right)$} & \multirow[b]{2}{*}{ Initial glucose concentration $(\%)$} & \multicolumn{2}{|c|}{ Productivity (g/L.h) } & \multicolumn{2}{|c|}{ Glucose consumption (g/L.h) } \\
\hline & & Low salinity & High salinity & Low salinity & High salinity \\
\hline \multirow[t]{3}{*}{26} & 2.0 & $0.066 \pm 0.001^{\mathrm{ab}}$ & - & $0.156 \pm 0.008^{\mathrm{cd}}$ & - \\
\hline & 3.0 & $0.064 \pm 0.001^{\mathrm{ab}}$ & $0.047 \pm 0.002^{\mathrm{d}}$ & $0.176 \pm 0.010^{\mathrm{bc}}$ & $0.143 \pm 0.001^{\mathrm{d}}$ \\
\hline & 2.0 & $0.055 \pm 0.004^{c}$ & $0.046 \pm 0.001^{\mathrm{d}}$ & $0.197 \pm 0.008^{\mathrm{ab}}$ & $0.157 \pm 0.003^{\text {cd }}$ \\
\hline \multirow[t]{2}{*}{30} & 3.0 & $0.070 \pm 0.002^{\mathrm{a}}$ & $0.040 \pm 0.005^{\mathrm{d}}$ & $0.225 \pm 0.002^{\mathrm{a}}$ & $0.202 \pm 0.010^{\mathrm{ab}}$ \\
\hline & 4.0 & $0.060 \pm 0.002^{\mathrm{bc}}$ & $0.042 \pm 0.003^{\mathrm{d}}$ & $0.196 \pm 0.008^{\mathrm{b}}$ & $0.164 \pm 0.023^{\mathrm{cd}}$ \\
\hline
\end{tabular}

Different lower case letters correspond to statistical differences between the different trials 

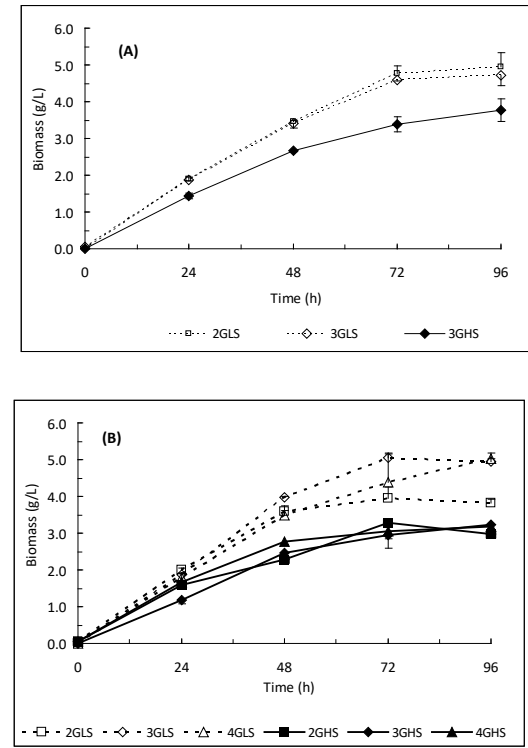

Figure 1: Evolution of biomass in Aurantiochytrium sp. cellular growth in trials with $2 \%(2 \mathrm{G}), 3 \%(3 \mathrm{G})$, and $4 \%(4 \mathrm{G})$ of glucose and salinity of $1.5 \%(\mathrm{LS})$ and $3.5 \%(\mathrm{HS})$ at $26^{\circ} \mathrm{C}(\mathrm{A})$ and $30^{\circ} \mathrm{C}(\mathrm{B})$.

A general increase of $\mathrm{pH}$ values was recorded in all experiments during cellular growth. The initial $\mathrm{pH}$ values were between 6.1 and 6.2 and a fast increase was recorded up to $6.9-7.0$ after 48 hours during the growth phase. After this growth period the $\mathrm{pH}$ values levelled off (high salinity at both temperatures) or only a small increase $(7.1-7.4)$ was recorded (low salinity at $30^{\circ} \mathrm{C}$ ). At the same temperature and after 72 hours, lower $\mathrm{pH}$ was recorded in the trials with high salinity, which is generally in line with the lower biomass recorded in these trials. The cellular growth at $30^{\circ} \mathrm{C}$ showed a higher $\mathrm{pH}$ then at $26^{\circ} \mathrm{C}$ for the lower salinity medium, but this effect of temperature was not so evident in the high salinity growth medium. On the other hand, no trend between the initial glucose concentration and $\mathrm{pH}$ values was observed during the experimental growth.

\section{Effect of growth conditions on squalene production}

The lipid content of this strain produced at the two salinities was similar $(35.0 \pm 0.7 \mathrm{~g} / 100 \mathrm{~g}$ for the $1.5 \%$ salinity and $33.8 \pm 3.9 \mathrm{~g} / 100 \mathrm{~g}$ for the $3.5 \%$ salinity). Triacylglycerols (TAG) was the most abundant lipid fraction $(66.6 \pm 0.6 \%$ and $64.5 \pm$ $0.9 \%$ for $1.5 \%$ and $3.5 \%$ salinity respectively). Squalene $(17.8 \pm$ $0.6 \%$ and $16.1 \pm 0.9 \%$ for $1.5 \%$ and $3.5 \%$ salinity respectively) was the second most important lipid constituent and its percentage in the oil was generally in accordance with its concentration determined in the biomass. The percentage of monoacylglycerols was $4.5 \pm 0.3 \%$ and $5.3 \pm 1.1 \%$ for $1.5 \%$ and $3.5 \%$ salinity respectively and that of diacylglycerols plus sterols accounted for $5.6 \pm 0.3 \%$ and $6.5 \pm 1.8 \%$ for $1.5 \%$ and $3.5 \%$ salinity respectively. In both microalgae biomass non-polar lipids represented more than $93 \%$ of total lipids. Free fatty acids were also detected but with very low percentage $(0.8 \pm 0.6 \%$ and $0.9 \pm 0.4 \%$ for $1.5 \%$ and $3.5 \%$ salinity respectively) whereas the percentage of PL was $4.7 \pm 0.7 \%$ and $6.6 \pm 0.8 \%$ for $1.5 \%$ and $3.5 \%$ salinity respectively and represented $16.5 \mathrm{mg} / \mathrm{g}$ and $22.3 \mathrm{mg} / \mathrm{g}$ of cell dry weight of biomass respectively.

The maximum squalene content was achieved after 48 hours [Figure 2A] but its decrease was more evident in the biomass obtained in the growth media presenting lower salinity. At $26^{\circ} \mathrm{C}$ [Figure 2B], the highest production of squalene was achieved in the trial with low salinity, $3 \%$ of glucose concentration after 48 hours. The highest squalene yields [Figure $2 \mathrm{C}$ ] were registered in the trials of $1.5 \%$ salinity as a result of the higher biomass achieved and its higher squalene content after 48 hours. Conversely, the maximum yield obtained in trials of 3.5\% salinity was lower and attained after 72 hours. On the other hand, the maximum yield productivity obtained at $26^{\circ} \mathrm{C}$ [Figure 2D] was about 1.5 times higher than the maximum value achieved at $30^{\circ} \mathrm{C}$. These results suggest that $26^{\circ} \mathrm{C}$ and $1.5 \%$ salinity are the most appropriate conditions for the production of squalene by this strain.
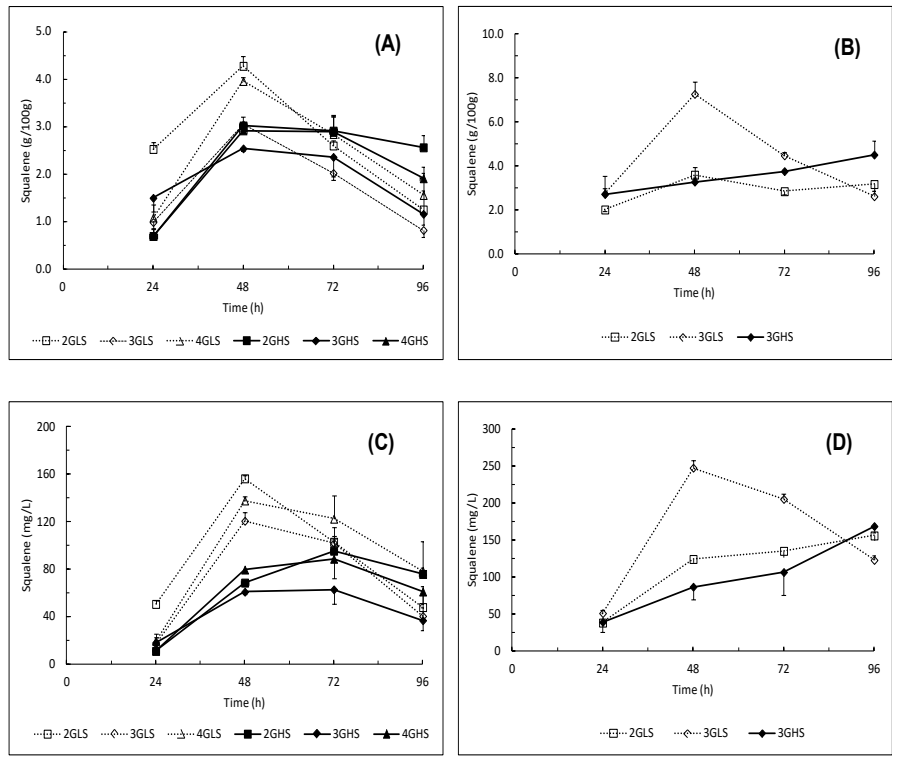

Figure 2: Evolution of biomass squalene content produced in trials at $30^{\circ} \mathrm{C}(\mathrm{A})$ and $26^{\circ} \mathrm{C}(\mathrm{B})$ and squalene yield at $30^{\circ} \mathrm{C}(\mathrm{C})$ and $26^{\circ} \mathrm{C}(\mathrm{D})$.

\section{Effect of culture conditions on fatty acids production}

As can be seen in [Table 2], saturated fatty acids and PUFA account for almost all fatty acids and monounsaturated fatty acids are only residual. The main saturated fatty acids were 14:0, 15:0, 16:0, and 17:0 where the odd fatty acids represented more than $50 \%$ of this group. Within polyunsaturated fatty acids 22:5n6 (DPA n-6) and 22:6n-3 were the most representative. The sum of the percentages of DHA and DPA n- 6 is about $90 \%$ of the total PUFA and the percentage of DHA is almost the double of that of DPA n-6. A regular increase of the biomass PUFA content occurred until 96 hours followed by a levelling off until the end of the experiment [Figure 3A]. For instance, the PUFA content of biomass obtained in trials $2 \mathrm{GLS}$, 3GLS, and 4GHS after 168 hours was $332 \mathrm{mg} / \mathrm{g}, 361 \mathrm{mg} / \mathrm{g}$, and $258 \mathrm{mg} / \mathrm{g}$, respectively. At 96 hours of growth the highest concentration of PUFA was recorded in trials 3 GLS and 2GHS [Figure 3A] which was significantly higher than that recorded in the trial 4GHS. The lowest DHA and DPA n- 6 concentration was also obtained in trial 4GHS [Figures $3 \mathrm{C}$ and E]. Accordingly, the highest PUFA productivity was observed in trial 3GLS and the lowest in the trial 4GHS [Figure 3B]. In summary, it may be concluded that the highest productivity of PUFA, DHA and DPA n-6 [Figures 3B, $\mathrm{D}$, and $\mathrm{F}$ ] was recorded in the growth medium with low salinity and $3 \%$ of initial glucose concentration. 
Short title:

Production of Squalene and Fatty Acids

Table 2: Fatty acid profile ( $\%$ total fatty acids) of Aurantiochytrium sp. cultured at $30^{\circ} \mathrm{C}$ in different growth conditions after 96 hours.

\begin{tabular}{|c|c|c|c|c|c|}
\hline Fatty acids & $\begin{array}{c}2 \mathrm{GLS} \\
(\%)\end{array}$ & $\begin{array}{c}2 \mathrm{GHS} \\
(\%)\end{array}$ & $\begin{array}{c}\text { 3GLS } \\
(\%)\end{array}$ & $\begin{array}{c}3 \mathrm{GHS} \\
(\%)\end{array}$ & $\begin{array}{c}\text { 4GHS } \\
(\%)\end{array}$ \\
\hline $13: 00$ & $\begin{array}{c}1.28 \\
(0.06)\end{array}$ & $\begin{array}{c}1.25 \\
(0.30)\end{array}$ & $\begin{array}{c}0.76 \\
(0.14)\end{array}$ & $\begin{array}{c}1.35 \\
(0.26)\end{array}$ & $\begin{array}{c}1.42 \\
(0.31)\end{array}$ \\
\hline $14: 00$ & $\begin{array}{c}6.76 \\
(0.22)\end{array}$ & $\begin{array}{c}6.04 \\
(0.91)\end{array}$ & $\begin{array}{c}8.17 \\
(1.24)\end{array}$ & $\begin{array}{c}5.84 \\
(1.24)\end{array}$ & $\begin{array}{c}5.29 \\
(0.93)\end{array}$ \\
\hline $15: 00$ & $\begin{array}{l}24.22 \\
(2.96)\end{array}$ & $\begin{array}{l}25.43 \\
(3.19)\end{array}$ & $\begin{array}{l}17.00 \\
(1.29)\end{array}$ & $\begin{array}{l}24.72 \\
(1.13)\end{array}$ & $\begin{array}{l}25.17 \\
(2.40)\end{array}$ \\
\hline $16: 00$ & $\begin{array}{l}22.10 \\
(1.35)\end{array}$ & $\begin{array}{l}23.87 \\
(0.58)\end{array}$ & $\begin{array}{l}27.39 \\
(0.68)\end{array}$ & $\begin{array}{l}22.06 \\
(1.97)\end{array}$ & $\begin{array}{l}20.99 \\
(1.79)\end{array}$ \\
\hline $17: 00$ & $\begin{array}{c}3.87 \\
(0.45)\end{array}$ & $\begin{array}{c}5.54 \\
(0.17)\end{array}$ & $\begin{array}{c}2.86 \\
(0.07)\end{array}$ & $\begin{array}{c}4.99 \\
(0.60)\end{array}$ & $\begin{array}{c}5.30 \\
(0.29)\end{array}$ \\
\hline $18: 00$ & $\begin{array}{c}0.64 \\
(0.02)\end{array}$ & $\begin{array}{c}0.73 \\
(0.05)\end{array}$ & $\begin{array}{c}0.67 \\
(0.03)\end{array}$ & $\begin{array}{c}0.65 \\
(0.09)\end{array}$ & $\begin{array}{c}0.78 \\
(0.06)\end{array}$ \\
\hline 19:00 & $\begin{array}{c}0.69 \\
(0.01)\end{array}$ & $\begin{array}{c}0.61 \\
(0.03)\end{array}$ & $\begin{array}{c}0.64 \\
(0.02)\end{array}$ & $\begin{array}{c}0.58 \\
(0.02)\end{array}$ & $\begin{array}{c}0.48 \\
(0.03)\end{array}$ \\
\hline $21: 00$ & $\begin{array}{c}0.31 \\
(0.02)\end{array}$ & $\begin{array}{c}0.52 \\
(0.07)\end{array}$ & $\begin{array}{c}0.35 \\
(0.03)\end{array}$ & $\begin{array}{c}0.43 \\
(0.01)\end{array}$ & $\begin{array}{c}0.54 \\
(0.05)\end{array}$ \\
\hline $18: 4 n-3$ & $\begin{array}{c}0.25 \\
(0.01)\end{array}$ & $\begin{array}{c}0.26 \\
(0.01)\end{array}$ & $\begin{array}{c}0.27 \\
(0.01)\end{array}$ & $\begin{array}{c}0.33 \\
(0.03)\end{array}$ & $\begin{array}{c}0.30 \\
(0.03)\end{array}$ \\
\hline $20: 4 n-6$ & $\begin{array}{c}0.92 \\
(0.04)\end{array}$ & $\begin{array}{c}0.88 \\
(0.09)\end{array}$ & $\begin{array}{c}0.55 \\
(0.09)\end{array}$ & $\begin{array}{c}0.95 \\
(0.05)\end{array}$ & $\begin{array}{c}1.13 \\
(0.011)\end{array}$ \\
\hline $20: 4 n-3$ & $\begin{array}{c}0.58 \\
(0.02)\end{array}$ & $\begin{array}{c}0.69 \\
(0.06)\end{array}$ & $\begin{array}{c}0.57 \\
(0.04)\end{array}$ & $\begin{array}{c}0.72 \\
(0.08)\end{array}$ & $\begin{array}{c}0.68 \\
(0.07)\end{array}$ \\
\hline $20: 5 n-3$ & $\begin{array}{c}0.97 \\
(0.05)\end{array}$ & $\begin{array}{c}1.23 \\
(0.015)\end{array}$ & $\begin{array}{c}0.68 \\
(0.05)\end{array}$ & $\begin{array}{c}1.31 \\
(0.016)\end{array}$ & $\begin{array}{c}1.33 \\
(0.016)\end{array}$ \\
\hline $22: 5 n-6$ & $\begin{array}{c}13.31 \\
(1.95)\end{array}$ & $\begin{array}{l}11.26 \\
(1.60)\end{array}$ & $\begin{array}{c}13.83 \\
(0.97)\end{array}$ & $\begin{array}{l}11.45 \\
(0.65)\end{array}$ & $\begin{array}{c}11.79 \\
(1.53)\end{array}$ \\
\hline $22: 6 n-3$ & $\begin{array}{l}22.62 \\
(2.89)\end{array}$ & $\begin{array}{l}20.40 \\
(2.53)\end{array}$ & $\begin{array}{l}24.60 \\
(1.34)\end{array}$ & $\begin{array}{l}23.59 \\
(2.30)\end{array}$ & $\begin{array}{l}21.30 \\
(3.19)\end{array}$ \\
\hline Total SFA & $\begin{array}{l}59.88 \\
(5.01)\end{array}$ & $\begin{array}{l}64.00 \\
(4.49)\end{array}$ & $\begin{array}{l}57.90 \\
(2.99)\end{array}$ & $\begin{array}{l}60.63 \\
(3.45)\end{array}$ & $\begin{array}{l}60.06 \\
(5.13)\end{array}$ \\
\hline Total PUFA & $\begin{array}{l}39.04 \\
(4.96)\end{array}$ & $\begin{array}{l}35.25 \\
(4.47)\end{array}$ & $\begin{array}{l}40.73 \\
(2.66)\end{array}$ & $\begin{array}{l}38.64 \\
(3.23)\end{array}$ & $\begin{array}{l}37.60 \\
(5.11)\end{array}$ \\
\hline
\end{tabular}

In brackets is the standard deviation
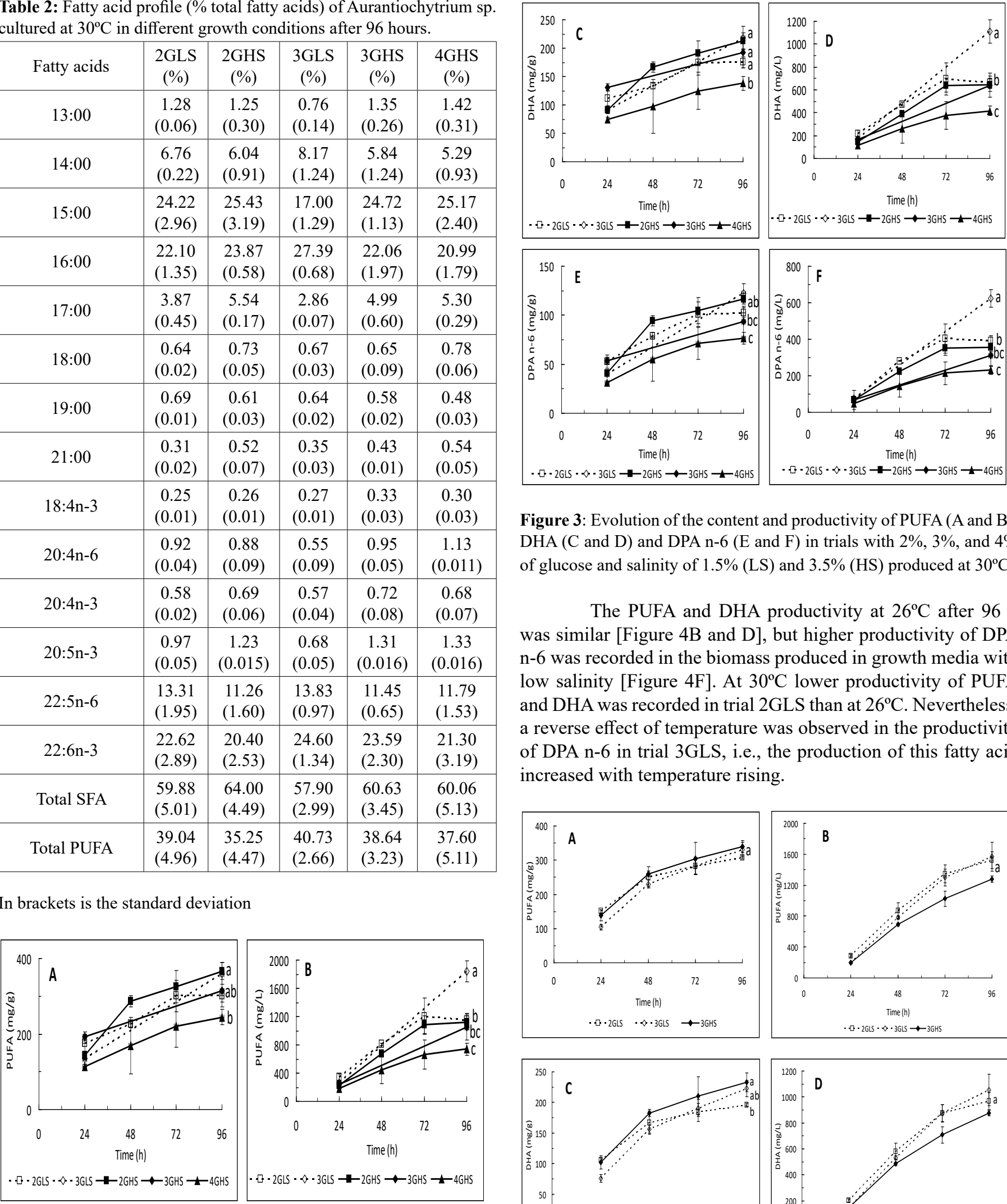

Figure 3: Evolution of the content and productivity of PUFA (A and B), DHA (C and D) and DPA n-6 (E and F) in trials with 2\%, 3\%, and 4\% of glucose and salinity of $1.5 \%(\mathrm{LS})$ and $3.5 \%(\mathrm{HS})$ produced at $30^{\circ} \mathrm{C}$.

The PUFA and DHA productivity at $26^{\circ} \mathrm{C}$ after $96 \mathrm{~h}$ was similar [Figure 4B and D], but higher productivity of DPA n- 6 was recorded in the biomass produced in growth media with low salinity [Figure $4 \mathrm{~F}$ ]. At $30^{\circ} \mathrm{C}$ lower productivity of PUFA and DHA was recorded in trial $2 \mathrm{GLS}$ than at $26^{\circ} \mathrm{C}$. Nevertheless, a reverse effect of temperature was observed in the productivity of DPA n-6 in trial 3GLS, i.e., the production of this fatty acid increased with temperature rising.
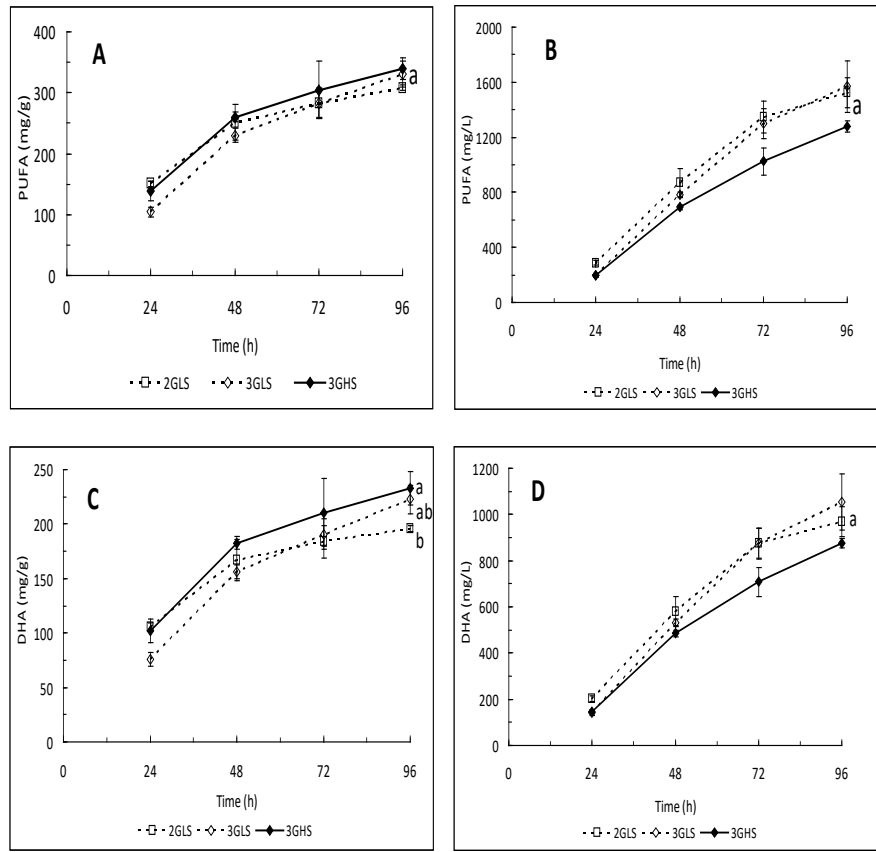

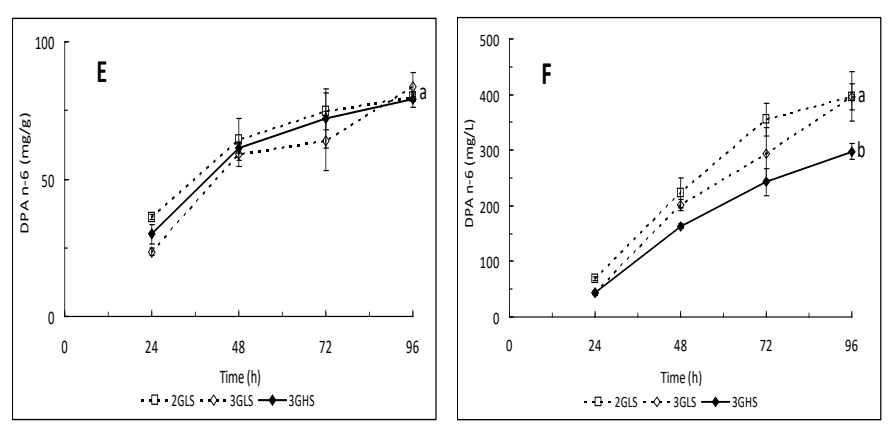

Figure 4: Evolution of the content and productivity of PUFA (A and $\mathrm{B})$, DHA (C and D) and DPA n-6 (E and F) in trials with $2 \%$ and $3 \%$ of glucose, salinity of $1.5 \%$ (LS) and $3.5 \%$ (HS) produced at $26^{\circ} \mathrm{C}$.

\section{Discussion}

The effect of salinity on the growth of Aurantiochytrium species have been reported in several works. Thus, small changes of the cell growth of Schizochytrium limacinum SR21 in the range between $50 \%$ and $200 \%$ of artificial seawater were observed $^{[14]}$. In a later work ${ }^{[15]}$ was reported that a mutant of that strain grew better and the biomass remained fairly constant with salinity at $1.8-3.6 \%(\mathrm{w} / \mathrm{v})$ but the growth of cells was inhibited for salinities below $0.9 \%$. Aurantiochytrium limacinum mh0186 presented good growth in artificial seawater with concentrations between $12.5-200 \%$ but it was suppressed in $0 \%$ seawater treatment ${ }^{[16]}$. The Aurantiochytrium sp. 18W-13a strain showed no significant changes at $25-100 \%$ natural seawater concentrations ${ }^{[17]}$. Similarly, a stable biomass production of $A$. mangrovei strain BL10 across salinity levels from $0.2 \%$ to $3.0 \%$ was obtained.4 Conversely, the highest biomass production of Thraustochytrium aureum was achieved at a salinity of 0.5 times the salinity of seawater ${ }^{[18]}$ or the maximum dry cell weight was recorded at a $\mathrm{NaCl}$ concentration of $15 \mathrm{~g} / \mathrm{L}$ in artificial seawater ${ }^{[19]}$.

No significant differences in the biomass produced in the trials performed at the two temperatures was recorded but a maximum biomass production of $S$. limacinum at $25^{\circ} \mathrm{C}$ and a salt concentration $50 \%$ of artificial seawater was reported ${ }^{[14]}$. On the other hand, the biomass of S. limacinum OUC88 presented only slight fluctuations when growing at $16-30^{\circ} \mathrm{C}$ but at $37^{\circ} \mathrm{C}$ the cell growth was considerably limited ${ }^{[15]}$. Similarly, it was observed that the cultures of an Aurantiochytrium sp. strain grew well at $15-30^{\circ} \mathrm{C}$ but not at 5 and $40^{\circ} \mathrm{C}(20)$. Other Aurantiochytrium sp. $\mathrm{Strain}^{[17]}$ grew well at a temperature range from $10^{\circ} \mathrm{C}$ to $30^{\circ} \mathrm{C}$ but at $35^{\circ} \mathrm{C}$ its growth sharply declined and the authors considered that the optimum temperatures were $15^{\circ} \mathrm{C}$ for the yield and $30^{\circ} \mathrm{C}$ for the growth rate.

A linear decrease of the glucose consumption was recorded during cellular growth with exception of trials 2 GLS and 3GLS where fast glucose consumption was recorded after 48 hours of growth. As shown in Table 1 the highest glucose consumption was recorded in trial $3 \mathrm{GLS}\left(30^{\circ} \mathrm{C}\right)$ although it was not significantly different from those recorded in trials 2 GLS and $3 \mathrm{GHS}$ performed at the same temperature. This high glucose consumption in $3 \mathrm{GHS}$ trial is also in accordance with the higher productivity recorded in this trial. Increasing biomass production of Schizochytrium sp. strain with glucose concentrations between 60 and $150 \mathrm{~g} / \mathrm{L}$ were obtained ${ }^{[2]}$. Some delay in the growth of this strain was only observed at the highest glucose concentration. A maximum biomass production of S. limacinum at $9 \%$ glucose and a growth inhibition at $12 \%$ glucose was reported ${ }^{[14]}$. Other authors have observed that an increase of the initial glucose concentration in the growth medium generally increased the biomass production of different Schizochytrium strains $^{[22]}$ or A. Mangrovei ${ }^{[4]}$. A gradual increase of the latter biomass strain with increasing glucose concentration was reported but it levelled off at $10 \%{ }^{[23]}$. The $\mathrm{pH}$ increase observed during growth of Aurantiochytrium sp. TC20 strain may result from the de-amination of amino acids such as it has been suggested that these species co-metabolize glucose and amino acids ${ }^{[24]}$. Microorganisms have the capacity of accumulating large amounts of oil and in the case of thraustochytrids it has been reported lipid contents from $17.1 \%{ }^{[17]}$ until levels above $50 \%$ of their dried biomass ${ }^{[25,26]}$. The presence of high percentages of TAG is common in single cell oil ${ }^{[5]}$ but considerably high percentages as 93.2 have been reported ${ }^{[25]}$. This abundance of TAG observed in microalgae and other microorganisms during the resting phase has been associated with nitrogen deficiency or ending of cellular division ${ }^{[25]}$. The percentage of monoacylglycerols obtained in the current work was similar to that reported by Fan et al. ${ }^{[25]}$ but these authors obtained a diacylglycerol percentage almost three fold higher. The percentage of PL was overestimated because they were not separated from pigments under the elution conditions followed in the lipid class separation. However, they were of the same order of magnitude of the value reported by Fan et $a l .{ }^{[25]}$ for the PL percentage. On the other hand, the PL levels in the biomass were of the same order of magnitude (23.4 $\mathrm{mg} / \mathrm{g}$ ) of that also reported ${ }^{[25]}$. The occurrence of a maximum squalene content followed by a decline due to its conversion to other compounds was also reported by several authors ${ }^{[27,28]}$. Previous work ${ }^{[6]}$ has reported the production of biomass with the highest squalene content of $0.72 \mathrm{mg} / \mathrm{g}$ and $5.90 \mathrm{mg} / \mathrm{L}$ in shaking flasks with $3 \%$ of initial glucose concentration. More recently it was reported ${ }^{[29]}$ the production of $S$. mangrovei biomass with a squalene content of $33.04 \mathrm{mg} / \mathrm{g}$ and a yield of $1.019 \mathrm{~g} / \mathrm{L}$. However, the highest reported squalene concentration was $198 \mathrm{mg} / \mathrm{g}$ with a yield of $1.29 \mathrm{~g} / \mathrm{L}^{[26]}$.

Similar fatty acid profile was reported in several works ${ }^{[15,16,27]}$ but it is quite noticeable the high percentage ( $c a$. $30 \%$ ) of odd fatty acids produced by Aurantiochytrium sp. These differences of fatty acid composition within thraustochytrids may result from a variety of factors including the thraustochytrid strain, growth conditions, and age of culture as mentioned $^{[27]}$. The high percentages of DHA and DPA $n-6$ obtained is typical of thraustochytrids and it is considered a signature fatty acid of Labyrinthulomycetes ${ }^{[30]}$. Higher DHA production with increasing levels of glucose was also reported ${ }^{[14]}$. However, in the current work a reversal trend was observed in the higher salinity growth media where the highest productivity of PUFA was achieved in the trial 2 GHS. These results may be due to a salt adaptation process of this microorganism as also mentioned by Zhu et al..$^{[15]}$. Concerning the effect of temperature on the production of PUFA, the results obtained agree with those reported by other authors ${ }^{[15,20]}$ who also obtained a decrease of DHA and an increase of DPA n-6 production with temperature rise. For these authors the increase of DHA content at lower temperatures is a result of an adaptation process to temperature, as well as to 
salinity to maintain the normal membrane lipid physical state.

Current study brings together the study of squalene and

DHA and represents a first step towards a more thorough utilization of the microrganism's biomass, which would be favoured by striking an adequate balance between both important compounds. Though further studies in the direction of the application of a holistic bio-refinery concept to the culture of Aurantiochytrium $s p$ are warranted, it seems that this more environmentally sustainable approach is viable, given the high observed squalene and DHA biomass productivities.

\section{Conclusions}

This study has investigated the effect of salinity, initial glucose concentration and temperature on the growth, squalene content and fatty acid profile of Aurantiochytrium sp. The highest biomass productivity was achieved after 72 hours of growth in the medium with $1.5 \%$ salinity and 2.0 or $3.0 \%$ of initial glucose concentration. Triacylglycerols was the main lipid class $(65 \%)$ followed by squalene (17\%). Saturated fatty acids and PUFA represented about $98 \%$ of total fatty acids and PUFA accounted for about $38 \%$. Residual amounts of monounsaturated fatty acids were recorded and the odd fatty acids were $c a$. 30\%. DHA and DPA n- 6 were the most abundant PUFA and the sum of their percentages was about $90 \%$ of PUFA. The maximum squalene content was achieved in the biomass produced in the growth medium with $1.5 \%$ salinity, $3.0 \%$ of initial glucose concentration at $26^{\circ} \mathrm{C}$ after 48 hours. The highest production of PUFA was attained after 96 hours of growth followed by a leveling off until the end of the experiment. The growth medium with $1.5 \%$ salinity and $3.0 \%$ of initial glucose concentration at $30^{\circ} \mathrm{C}$ after 96 hours led to the highest productivity of PUFA, DHA, and DPA $\mathrm{n}-6$. On the basis of the favourable conditions for squalene and DHA production, it seems possible to choose culture conditions in a way that improves squalene and DHA productivity.

Acknowledgements: This work was funded by the project "Valorização dos subprodutos do processo biotecnológico de produção de esqualeno e DHA pela microalga Aurantiochytrium sp." (AlgaValue) (ref. 17680) and operational programme Portugal 2020 supported by European Regional Development Fund (ERDF).

\section{References}

1. Fox CB. Squalene emulsions for parenteral vaccine and drug delivery. (2009) Molecules 14(9): 3286-3312.

Pubmed | Crossref | Others

2. Budiyanto, A., Ahmed, N.U., Wu ,A., et al. Protective effect of topically applied olive oil against photocarcinogenesis following UVB exposure of mice. (2000) Carcinogenesis 21(11): 2085-2090.

Pubmed | Crossref | Others

3. Newmark, H.L. Squalene, olive oil and cancer - review and hypothesis. (1999) Cancer Epidemiol Biomarkers Prev 889: 193-203.

Pubmed | Crossref | Others

4. Chaung, K.C., Chu, C.Y., Su, Y.M., et al. Effect of culture conditions on growth, lipid content, and fatty acid composition of Aurantiochytrium mangrovei strain BL10. (2012) AMB Ex- press 2(1): 42 .

Pubmed | Crossref | Others

5. Ratledge, C. Fatty acid biosynthesis in microorganisms being used for single cell oil production. (2004) Biochimie 86: 807-815.

Pubmed | Crossref | Others

6. Chen, G., Fan, K.W., Lu, F.P., et al. Optimization of nitrogen source for enhanced production of squalene from thraustochytrid Aurantiochytrium sp. (2010) N Biotechnol 27(4): 382-389. Pubmed | Crossref | Others

7. Miller GL. Use of dinitrosalicylic acid reagent for determination of reducing sugar. (1959) Anal Chem 31(3): 426-428.

Pubmed | Crossref | Others

8. Bligh, E., Dyer, W. Rapid method of total lipid extraction and purification. (1959) Can J Biochem Physiol 37(8): 911-917.

Pubmed | Crossref | Others

9. Costa, S., Afonso, C., Cardoso, C., et al. Fatty acids, mercury, and methylmercury bioaccessibility in salmon (Salmo salar) using an in vitro model: Effect of culinary treatment. (2015) Food Chem 185: 268-276.

Pubmed | Crossref | Others

10. Lepage, G., Roy, C.C. Direct transesterification of all classes of lipids in a one-step reaction. (1986) J Lipid Res 27(1): 114120.

Pubmed | Crossref | Others

11. Cohen, Z., Vonshak, A., Richmond, A. Effect of environmental conditions on fatty acid composition of the red algae Porphyridium cruentum: correlation to growth rate. (1988) J Phycol 24(3): 328-332.

Pubmed | Crossref | Others

12. Bandarra, N.M., Pereira, P.A., Batista, I., et al. Fatty acids, sterols and $\alpha$-tocopherol in Isochrysis galbana. (2003) J Food Lipids 10(1): 25-34.

Pubmed | Crossref | Others

13. Zar, J.H. Biostatistical Analysis (fourth ed.) Upper Saddle River (1999) NJ: Prentice-Hall, Inc.

Pubmed | Crossref | Others

14. Yokochi, T., Honda, D., Higashihara, T., et al. Optimization of docosahexaenoic acid production by Schizochytrium limacinum SR21. (1998) Appl Microbiol Biotechnol 49(1): 72-76.

Pubmed | Crossref | Others

15. Zhu, L., Zhang, X., Ji, L., et al. Changes of lipid content and fatty acid composition of Schizochytrium limacinum in response to different temperatures and salinities. (2007) Process Biochem 42(2): 210-214.

Pubmed | Crossref | Others

16. Nagano, N., Taoka, Y., Honda, D., et al. Optimization of culture conditions for growth and docosahexaenoic acid production by a marine thraustochytrid, Aurantiochytrium limacinum mh0186. (2009) J Oleo Sci 58(12): 623-628.

Pubmed | Crossref | Others

17. Nakazawa, A., Matsuura, H., Kose, R., et al. Optimization of culture conditions of the thraustochytrid Aurantiochytrium sp. strain 18W-13a for squalene production. (2012) Bioresource Technol 109: 287-291.

Pubmed | Crossref | Others

18. Iida, I., Nakahara, T., Yokochi, T., et al. Improvement of docosahexaenoic acid production in a culture of Thraustochytrium aureum by medium optimization. (1996) J Ferment Bioeng 81(1): 76-78. 
Pubmed | Crossref | Others

19. Min, K.H., Lee, H.H., Anbu, P., et al. The effects of culture condition on the growth property and docosahexaenoic acid production from Thraustochytrium aureum ATCC 34304. (2012) Korean J Chem Eng 29(9): 1211-1215.

Pubmed | Crossref | Others

20. Taoka, Y., Nagano, N., Okita, Y., et al. Influences of culture temperature on the growth, lipid content and fatty acid composition of Aurantiochytrium sp. strain mh0186. (2009) Mar Biotechnol 11(3): 368-374.

Pubmed | Crossref | Others

21. Yaguchi, T., Tanaka, S., Yokochi, T., et al. Production of high yields of docosahexaenoic acid by Schizochytrium sp. strain SR21. (1997) JAOCS 74(1): 1431-1434.

Pubmed | Crossref | Others

22. Unagul, P., Assantachai, C., Phadungruengluij, S., et al. Properties of the docosahexaenoic acid-producer Schizochytrium mangrovei Sk-02: effects of glucose, temperature and salinity and their interaction. (2005) Bot Mar. 48(5-6): 387-394.

Pubmed | Crossref | Others

23. Wong, M.K., Tsui, C.K., Au, D.W., et al. Docosahexaenoic acid production and ultrastructure of the thraustochytrid Aurantiochytrium mangrovei MP2 under high glucose concentrations. (2008) Mycoscience 49(4): 266-270.

Pubmed | Crossref | Others

24. Chang, K.J., Dumsday, G., Nichols, P.D., et al. High cell density cultivation of a novel Aurantiochytrium sp. strain TC 20 in a fed-batch system using glycerol to produce feedstock for biodiesel and omega-3 oils. (2013) Appl Microbiol Biotechnol 97(15): 6907-6918.

Pubmed | Crossref | Others

25. Fan, K.W., Jiang, Y., Faan, Y.W., et al. Lipid characterization of mangrove thraustochytrid - Schizochytrium mangrovei. (2007) J Agric Food Chem 55(8): 2906-2910.

Pubmed | Crossref | Others

26. Kaya, K., Nakazawa, A., Matsuura, H., et al. Thraustochytrid Aurantiochytrium sp. 18W-13a accumulates high amounts of squalene. (2011) Biosci Biotechnol Biochem 75(11): 22462248.

Pubmed | Crossref | Others

27. Jiang, Y., Fan, K.W., Wong, R.T., et al. Fatty acid composition and squalene content of the marine microalga Schizochytrium mangrovei. (2004) J Agric Food Chem 52(5): 1196-1200. Pubmed | Crossref | Others

28. Fan, K.W., Aki, T., Chen, F., et al. Enhanced production of squalene in the thraustochytrid Aurantiochytrium mangrovei by medium optimization and treatment with terbinafine. (2010) World J Microbiol Biotechnol 26(7): 1303-1309.

Pubmed | Crossref | Others

29. Hoang, M.H., Ha, N.C., Thom, L.T., et al. Extraction of squalene as value-added product from the residual biomass of Schizochytrium mangrovei PQ6 during biodiesel producing process. (2014) J Biosci Bioeng 118(6): 632-639.

Pubmed | Crossref | Others

30. Huang, J., Aki, T., Yokochi, T., et al. Grouping newly isolated docosahexaenoic acid-producing thraustochytrids based on their polyunsaturated fatty acid profiles and comparative analysis of 18S rRNA genes. (2003) Mar Biotechnol 5(5): 450-457. Pubmed | Crossref | Others
Submit your manuscript to Ommega Publishers and we will help you at every step:

- We accept pre-submission inquiries

- Our selector tool helps you to find the most relevant journal

- We provide round the clock customer support

- Convenient online submission

- Thorough peer review

- Inclusion in all major indexing services

- Maximum visibility for your research

Submit your manuscript at

https://www.ommegaonline.org/submit-manuscript 